\title{
REHABILITASI KOLAM MILIK MASYARAKAT UNTUK BUDIDAYA IKAN AIR TAWAR SEBAGAI UPAYA PENINGKATAN INFRASTRUKTUR PENUNJANG DI RW O2 KELURAHAN MUARA FAJAR BARAT
}

\author{
Rizki Ramadhan Husaini ${ }^{1)}$, Fitra Ramdhani' ${ }^{2)}$, Sukri ${ }^{3)}$ \\ ${ }^{1,2)}$ Program Studi Teknik Sipil Universitas Abdurrab \\ ${ }^{3)}$ Program Studi Teknik Informatika Universitas Abdurrab \\ Email: rizki.ramadhan@univrab.ac.id
}

\begin{abstract}
ABSTRAK
Pembangunan infrastruktur penunjang merupakan hal yang penting bagi pengembangan suatu wilayah pedesaan. Infrastuktur penunjang tersebut bisa seperti taman, kolam maupun bangunan yang diperuntukkan untuk umum. Kegiatan Kuliah Kerja Nyata (KUKERTA) Universitas Abdurrab bertujuan untuk mengidentifikasi masalah, mengalanisis masalah dan memberikan solusi terhadap masalah di wilayah kerja. Permasalahan yang ada RW 02 Kelurahan Muara Fajar Barat Kecamatan Rumbai Kota Pekanbaru yaitu memiliki kolam milik masyarakat yang tidak terawat. Hal tersebut sangat disayangkan karena kolam tersebut merupakan infrastruktur penunjang perumahan yang memiliki potensi untuk dimanfaatkan bagi masyarakat sekitar. Melalui program kerja Kelompok 15 Kuliah Kerja Nyata (KUKERTA) Universitas Abdurrab Tahun 2019 melakukan program rehabilitasi kolam milik masyarakat sebagai upaya peningkatan infrastruktur penunjang. Metode pelaksanaan kegiatan rehabilitasi kolam milik masyarakat ini adalah dengan melakukan penyuluhan terhadap warga bahwa pentingnya infrastruktur penunjang dan mengajak warga untuk melakukan rehabilitasi kolam bersama. Hasil yang dicapai dari program ini adalah kolam milik masyarakat yang awalnya ditumbuhi semak belukar sekarang dapat dimanfaatkan oleh masyarakat sekitar sehingga dapat digunakan untuk peternakan ikan air tawar dan diharapkan masyarakat dapat mengambil hasil panen ikan tersebut.
\end{abstract}

Kata kunci: Infrastruktur, Penunjang, Rehabilitasi, Kolam, Ikan

\section{ABSTRACT}

The development of supporting infrastructure is important for the development of a rural area. Supporting infrastructure can be like parks, ponds and buildings that are intended for the public. Abdurrab University's Real Work Lecture (KUKERTA) activity aims to identify problems, analyze problems and provide solutions to problems in the work area. The problem is that RW 02 Kelurahan Muara Fajar Barat, Rumbai District, Pekanbaru City is having a pool that is not maintained by the community. This is very unfortunate because the pool is a housing support infrastructure that has the potential to be utilized for the surrounding community. Through the work program of the Group 15 Real Work Lecture (KUKERTA) Abdurrab University in 2019 conducted a community pool rehabilitation program as an effort to improve supporting infrastructure. The method for carrying out community rehabilitation activities is to educate residents about the importance of supporting infrastructure and invite residents to carry out joint pool rehabilitation. The results achieved from this program are community-owned ponds which were originally covered with shrubs can now be utilized by the surrounding community so that they can be used for freshwater fish farming and it is hoped that the community can take the fish harvest

Key words: Infrastructure, Support, Rehabilitation, Pond, Fish 


\section{PENDAHULUAN}

Kecamatan Rumbai merupakan salah satu kecamatan di wilayah Kota Pekanbaru, terdiri atas $63 \mathrm{RW}$ dan $252 \mathrm{RT}$. Luas wilayah Kecamatan Rumbai adalah 128,85 Km². Kecamatan Rumbai terdiri dari sembilan kelurahan, 74 RW dan 280 RT. Sembilan Kelurahan tersebut adalah : Kelurahan Umban Sari, Kelurahan Rumbai Bukit, Kelurahan Muara Fajar Barat, Muara Fajar Timur, Agro Wisata, Maharani, Rantau Panjang, Kelurahan Palas, dan Kelurahan Sri Meranti dengan Kepala Keluarga pada tahun 2017 sebanyak 15.668 (BPS, 2018).

Kelurahan muara Fajar Barat merupakan salah satu kelurahan di wilayah Kecamatan Rumbai Kota Pekanbaru yang baru lahir pada tahun 2017. Sebelumnya kelurahan ini termasuk kedalam kelurahan Muara Fajar. Sejak tahun 2017 kelurahan Muara Fajar dipisah menjadi 2 bagian yaitu kelurahan Muara Fajar Barat dan kelurahan Muara Fajar Timur.

Pembangunan pedesaan harus dilakukan dengan pendekatan yang sesuai dengan sifat dan cirinya. Pembangunan pedesaan harus mengikuti empat upaya besar, satu sama lain saling berkaitan dan merupakan strategi pokok pembangunan pedesaan, yaitu: Pertama, memberdayakan ekonomi masyarakat desa. Dalam upaya ini diperlukan masukan modal dan bimbingan-bimbingan pemanfaatan teknologi dan pemasaran untuk memampukan dan memandirikan masyarakat desa; Kedua, meningkatkan kualitas sumberdaya manusia pedesaan agar memiliki dasar yang memadai untuk meningkatkan dan memperkuat produktivitas dan daya saing; Ketiga, pembangunan prasarana di pedesaan. Untuk daerah pedesaan prasarana perhubungan merupakan kebutuhan yang mutlak, karena prasarana perhubungan akan memacu ketertinggalan masyarakat pedesaan; dan keempat, membangun kelembagaan pedesaan baik yang bersifat formal maupun nonformal. Kelembagaan yang dibutuhkan oleh pedesaan adalah terciptanya pelayanan yang baik terutama untuk memacu perekonomian pedesaan seperti lembaga keuangan (Syahza, 2013).

Kegiatan Kuliah Kerja Nyata (Kukerta) Universitas Abdurrab merupakan salah satu kegiatan pengabdian masyarakat yang bertujuan untuk mengidentifikasi masalah, mengalanisis masalah dan memberikan solusi terhadap masalah di wilayah kerja. Adapun wilayah kerja Kelompok 15 Kukerta Universitas Abdurrab Tahun 2019 ini berada di RW 02 Kelurahan Muara Fajar Barat.

Permasalahan yang ada RW 02 Kelurahan Muara Fajar Barat Kecamatan Rumbai Kota Pekanbaru yaitu memiliki kolam milik masyarakat yang tidak terawat. Hal tersebut sangat disayangkan karena kolam tersebut merupakan infrastruktur penunjang perumahan yang memiliki potensi perikanan untuk dimanfaatkan bagi masyarakat sekitar. Potensi perikanan yang besar tersebut dalam pemanfaatannya harus didukung oleh tersedianya sarana dan prasarana yang memadai, salah satunya adalah kolam yang baik. Melalui program kerja Kelompok 15 Kukerta Universitas Abdurrab tahun 2019 melakukan program rehabilitasi kolam milik masyarakat sebagai upaya peningkatan infrastruktur penunjang.

Kurangnya partisipasi dari kepemudaan dalam bergotong-royong membuat kolam ini menjadi terbengkalai. Kolam yang memiliki luas $120 \mathrm{~m}^{2}$ ini banyak ditanami rerumputan sehingga dikhawatirkan akan menjadi sarang hewan liar. Upaya yang dilakukan dalam rehabilitasi kolam ini diharapkan akan berguna sebagai tempat reservoar atau penampung air dalam ketika musim hujan.

Adapun tujuan umum dari kegiatan pengabdian ini adalah memberikan kesadaran bagi masyarakat khususnya kepemudaan dalam kegiatan kegotongroyongan. Selain itu 
manfaat dari kegiatan pengabdian ini adalah membuat kolam ini berfungsi sebagai infrastruktur penunjang pedesaan diwilayah ini.

\section{TINJAUAN PUSTAKA}

Air merupakan sumber daya alam yang sangat penting bagi manusia. Air sangat dibutuhkan untuk pertanian, perikanan, perkebunan, peternakan dan banyak kepentingan lainnya. Sejalan dengan pertumbuhan penduduk yang kian pesat, maka kebutuhan akan air juga meningkat. Karena itulah diperlukan sistem pengaturan air yang efisien, Untuk kebutuhan pertanian, air mutlak diperlukan dalam pengelolaannya. Untuk mewujudkan sistem pengairan yang baik diperlukan perencanaan jaringan irigasi yang baik pula.

Pemanfaatan sumber daya air dapat dilakukan hampir pada semua lini kehidupan manusia baik untuk keperluan hidup sehari-hari maupun untuk usaha yang menggunakan bahan dasar air atau sebagai penunjang, termasuk usaha di bidang pertanian. Pasal 8 UU No. 5 Tahun 1960 tentang Peraturan Dasar Pokok-Pokok Agraria (UUPA) menyatakan pengambilan kekayaan alam, termasuk air, harus diatur dengan peraturan perundangan. Pasal 41 UU No. 7 Tahun 2004 tentang Sumber Daya Air (UUSDA) disebutkan bahwa pemenuhan air baku untuk pertanian dilakukan dengan pengembangan sistem irigasi (Listyawati, 2011).

Pengelolaan sumber daya air merupakan pengelolaan sumberdaya alam dengan tujuan untuk memperbaiki, memelihara dan melindungi keadaan sumber daya air, agar dapat menghasilkan barang dan jasa khususnya kuantitas, kualitas dan kontinuitas air (water yield) untuk kepentingan pertanian kehutanan, perkebunan, peternakan, perikanan, industri dan masyarakat (Khairuddin, 2012).

Pengembangan masyarakat merupakan kegiatan yang dilakukan bersama komunitas masyarakat dengan cara meningkatkan partisipasi aktif masyarakat dalam rangka memenuhi kebutuhan hidup dan menyelesaikan persoalan-persoalan yang dialami oleh komunitas masyarakat (Darmansyah, 2016). Program pengembangan masyarakat dapat dilakukan berdasarkan kearifan lokal berupa peningkatan partisipasi masyarakat dan berjalan secara berkelanjutan (Amanah, 2005). Kegiatan pengembangan masyarakat dapat berupa peningkatan keterampilan melalui pelatihan peningkatan kemampuan dalam mengolah sumber daya alam (Ihsan, 2002). Pemberdayaan masyarakat merupakan hal yang penting untuk dilakukan karena melalui pemberdayaan, kehidupan masyarakat menjadi lebih baik. Pemberdayaan yang dilaksanakan sesuai dengan prosedur dan model pemberdayaan partisipative salah satunya kegiatan pemberdayaan pembudidaya ikan (Zulkarnain, 2015).

\section{METODE PELAKSANAAN \\ Tahapan Pelaksanaan}

Kegiatan pengabdian ini dilaksanakan di RW 02 Kelurahan Muara Fajar Barat Kecamatan Rumbai Kota Pekanbaru dan berlangsung pada bulan Juli sampai dengan Agustus 2019. Bahan dan alat yang dibutuhkan selama kegiatan penyuluhan dan peralatan pembersihan kolam. Pelaksanaan kegiatan pengabdian dilakukan dengan kegiatan penyuluhan pentingnya pemanfaatan sumber daya air dari kolam. Selanjutnya tahapan pelaksanaan kegiatan pengabdian dilakukan sebagai berikut :

1. Pertemuan awal dengan kelompok

2. Persiapan dan penyerahan alat dan bahan pendukung kegiatan

3. Penyuluhan kepada masyarakat setempat

4. Pelaksanaan pembersihan kolam 
Keterlibatan masyarakat dan partisipasinya meliputi kegiatan gotong royong bersama dalam pembersihan kolam ikan yang dilakukan pada akhir pekan. Motode yang dipakai untuk mengerakan masyarakat guna membersihkan kolam dengan memberikan surat undangan ke rumah rumah warga. Adapun waktu dan tempat pelaksanaan kegiatan pengabdian ini adalah sebagai berikut

1. Waktu pelaksanaan

- Tahap awal pembersihan kolam, tanggal : Minggu 14 Juli 2019

- Tahap selanjutnya sampai selesai, tanggal : 21 Juli sampai 3 agustus 2019

2. Tempat

Kolam ikan di RW 02

3. Alat yang digunakan

- Parang

- Sabit

- Tali tambang

- Cangkul

\section{Evaluasi dan Kriteria Keberhasilan}

Evaluasi terhadap pelaksanaan kegiatan dilakukan sebelum dan sesudah kegiatan penyuluhan dan pelatihan berakhir. Untuk mengukur tingkat keberhasilan kegiatan dilakukan workshop hasil kegiatan program kerja yang dilaksanakan pada minggu terakhir kegiatan Kukerta.

\section{HASIL DAN PEMBAHASAN Kegiatan Persiapan}

Tahap awal pelaksanaan program pengabdian ini dilakukan dengan mengidentifikasi masalah dari wilayah kerja. Adapun permasalahan yang ada dilapangan adalah kolam ikan milik masyarakat yang tidak berfungsi lagi. Kolam ikan yang ada sudah banyak ditumbuhi rumput liar sehingga menjadi lahan rawa yang dikhawatirkan akan menjadi sarang binatang liar.

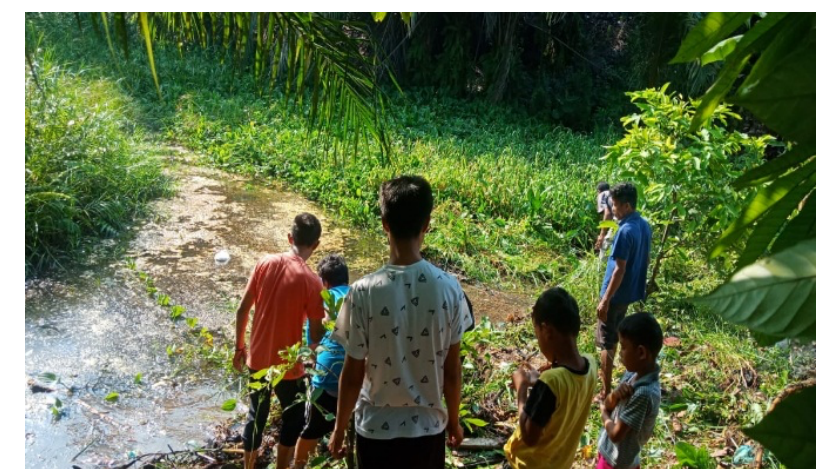

Gambar 1. Kolam Ikan yang Banyak Ditanami Rumput

Kolam ikan milik masyarakat ini memiliki luas $120 \mathrm{~m}^{2}$ sehingga dapat menampung ikan yang relatif banyak. Untuk kolam ikan air tawar ini bisa dimanfaatkan sebagai peternakan ikan lele, patin, nila dan sebagainya. Pemanfaatan sumber daya air dengan merehabilitasi kolam ikan ini dapat menghidupkan tingkat sosial dan ekonomi masyarakat sekitar. 


\section{Kegiatan Pelaksanaan}

Pelaksanaan dalam merehabilitasi kolam ikan milik masyarakat ini dilakukan dengan partisipasi masyarakat RW 02 Keluarah Muara Fajar Barat. Semangat gotongroyong yang ditumbuhkan oleh mahasiswa Kukerta Universitas Abdurrab. Kegiatan pelaksanaan rehabilitasi kolam ini dilakukan pada akhir pekan bersama masyarakat RW 02 Kelurahan Muara Fajar Barat karena mengingat masyarakat yang pada umumnya sudah bekerja. Kegiatan ini berjalan selama 3 minggu dan setiap minggu dilakukan kontrol terhadap progress pekerjaan pembersihan kolam

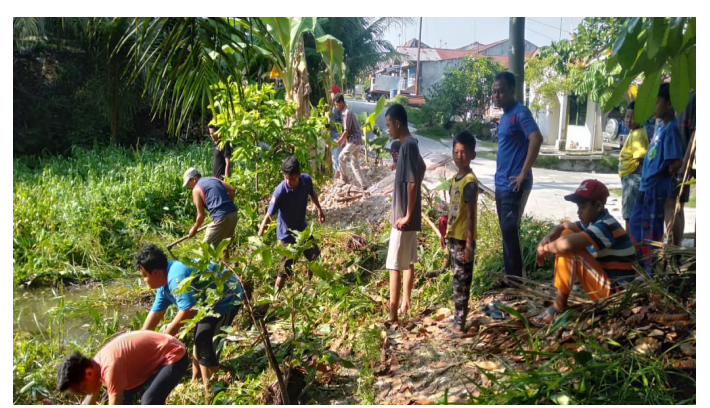

Gambar 2. Kegiatan Rehabilitasi Kolam Bersama Masyarakat RW 02 Kelurahan Muara Fajar Barat

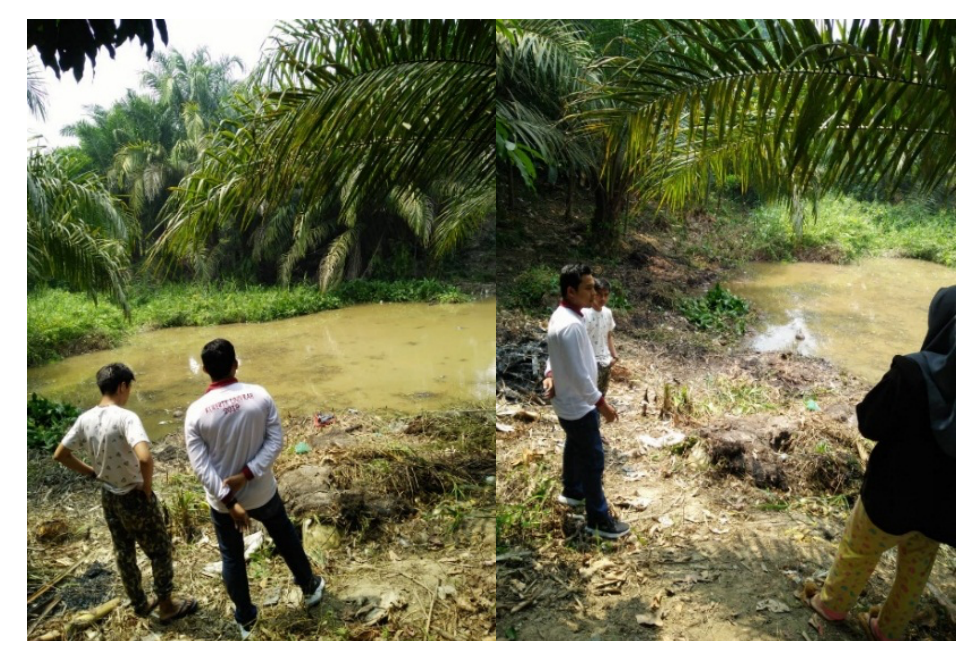

Gambar 3. Kegiatan Kontrol Program Kerja

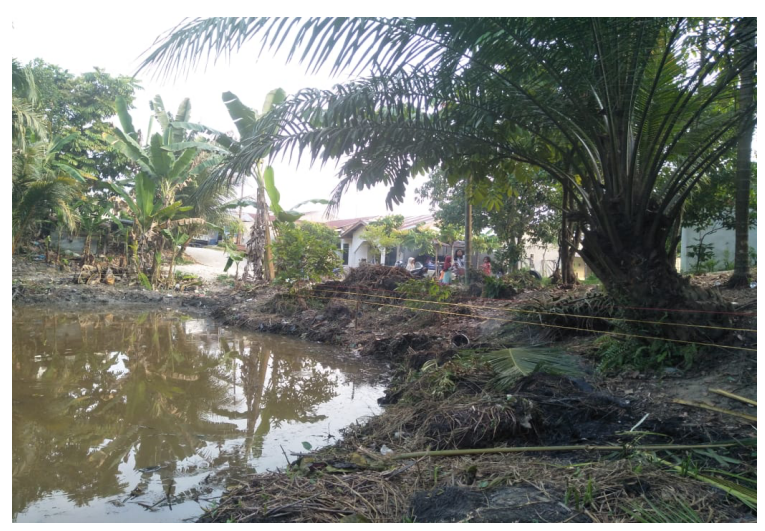

Gambar 4. Kolam yang Sudah di Bersihkan 
Berdasarkan hasil dari program pengabdian ini maka diperoleh kolam yang sudah dibersihkan dan akan dibuat kerambah untuk membudidaya ikan. Sebagai tambahan pada daerah pinggiran (bantaran) kolam dapat dibuat taman yang dapat mempercantik fasilitas kolam ikan ini.

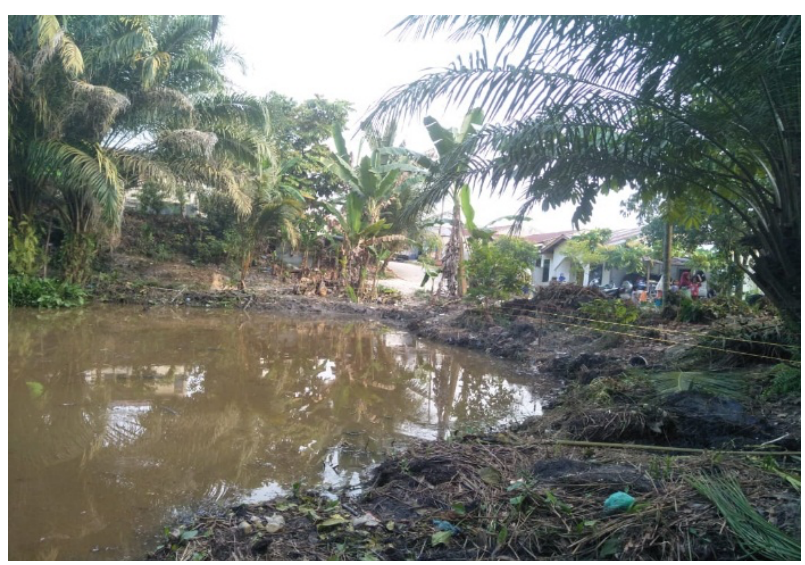

Gambar 5. Bentuk kolam yang akan di buat kerambah

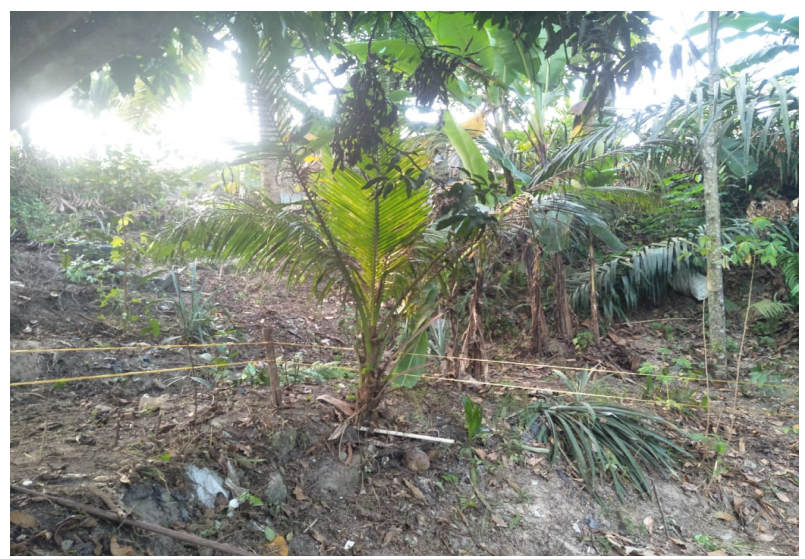

Gambar 6. Lokasi Pembuatan Kebun

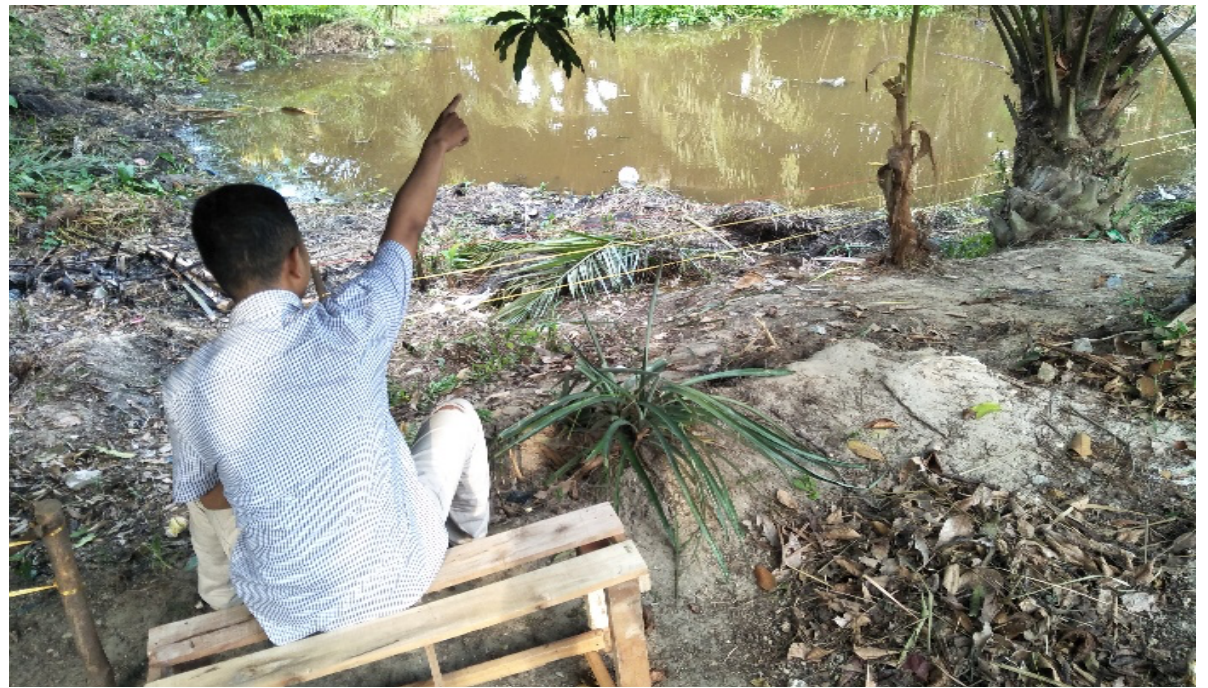

Gambar 7. Pinggiran Kolam yang Akan Dibuatkan Taman 


\section{KESIMPULAN}

Berdasarkan hasil evaluasi pelaksanaan kegiatan rehabilitasi kolam milik masyarakat untuk budidaya ikan air tawar sebagai upaya peningkatan infrastruktur penunjang di RW 02 Kelurahan Muara Fajar Barat, dapat disimpulkan bahwa tingkat partisipasi masyarakat bersama anggota kelompok Kukerta Universitas Abdurrab yang tinggi memberikan dampak positif bagi pelaksanaan program pengabdian ini, terlihat dari kegiatan pembersihan kolam yang semula ditumbuhi rumput menjadi lebih bersih.

Dari hasil workshop yang telah dilakukan masyarakat mengucapkan terima kasih atas dilakukannya kegiatan pengabdian ini. Masyarakat RW 02 Kelurahan Muara Fajar Barat mengharapkan keberlanjutan dari pembangunan kolam ini seperti pembuatan taman sekitar kolam, gazebo dan infrastruktur penunjang lainnya.

Selain itu penyuluhan tentang pentingnya pemanfaatan sumber daya air telah meningkatkan pengetahuan masyarakat RW 02 Kelurahan Muara Fajar Barat, yang ditunjukkan dengan adanya keikutsertaan masyarakat dalam rehabilitasi kolam sebagai infrastruktur penunjang pedesaan ini.

\section{DAFTAR PUSTAKA}

[1]. Amanah S. 2005. Pengembangan responden pesisir berdasarkan kearifan lokal di pesisir kabupaten Bulelelng di Provinsi Bali.[disertasi]. Bogor (ID) Sekolah Pascasarjana. Institut Pertanian Bogor.

[2]. Darmansyah A, Sulistiono, Nugroho T, Supriyono E. 2016). Pemberdayaan masyarakat melalui pengembangan budidaya ikan lele di Desa Balongan, Indramayu, Jawa Barat. Jurnal Agrokreatif IPB. 2(1): 8-16

[3]. Ihsan YN. 2002. Kajian pengembangan budidaya laut (pengaruhnya terhadap kesejahteraan responden pesisir) studi kasus di kelurahan pulau panggang Kab. Seribu [Tesis]. Bogor (ID): Institut Pertanian Bogor

[4]. Khairuddin, Munir. 2012. Studi Pengembangan Budidaya Ikan Sistem Kolam Air Deras di Sungai Caramele Kota Parepare Sulawesi Selatan. Jurnal Galung Tropika, September 2012, hlmn. 36-45

[5]. Listyawati H. 2011. Konflik Pemanfaatan Sumber Daya Air Untuk Irigasi Di Kecamatan Minggir Kabupaten Sleman. Jurnal Mimbar Hukum Volume 23, Nomor 3, Oktober 2011, Halaman 431 - 645

[6]. Syahza A, Suarman. 2013. Strategi Pengembangan Daerah Tertinggal Dalam Upaya Percepatan Pembangunan Ekonomi Pedesaan. Jurnal Ekonomi Pembangunan Volume 14 Nomor 1, Juni 2013, hlm. 126-139

[7]. Undang - Undang No. 7 Tahun 2004 tentang Sumber Daya Air

[8]. Zulkarnain, 2015. Analisis Hubungan Jaringan Komunikasi Dengan Perubahan Taraf Penghidupan Dan Pola Pikir Dalam Pemberdayaan Pembudidaya Ikan Di Kabupaten Kampar, Riau. [disertasi]. Bogor (ID) Sekolah Pascasarjana. Institut Pertanian Bogor. 